Е. П. Берёзкина, А. Е. Томина. Тема смерти как олицетворение жизнеутверждающего смысла в романе Захара Прилепина «Грех»

УДК 821.161 .1 .0

DOI: 10.18101/2305-459X-2020-2-53-60

\title{
ТЕМА СМЕРТИ КАК ОЛИЦЕТВОРЕНИЕ ЖИЗНЕУТВЕРЖДАЮЩЕГО СМЫСЛА В РОМАНЕ ЗАХАРА ПРИЛЕПИНА «ГРЕХ»
}

\author{
(C) Берёзкина Елена Петровна \\ кандидат филологических наук, доцент, \\ Бурятский государственный университет имени Доржи Банзарова \\ Россия, 670000, г. Улан-Удэ, ул. Ранжурова, 6 \\ beryozkina-lena@yandex.ru

\section{(C) Томина Анна Евгеньевна} \\ обучающийся, \\ Бурятский государственный университет имени Доржи Банзарова \\ Россия, 670000, г. Улан-Удэ, ул. Ранжурова, 6 \\ anna.tomina999@yandex.ru
}

\begin{abstract}
Аннотация. В статье рассматривается тема смерти, становящаяся жизнеутверждающим началом, в романе Захара Прилепина «Грех». Его герой Захар показан юношей, взрослым мужчиной, мальчишкой, отцом своих сыновей, и на этих разных этапах своего становления он постоянно сталкивается со смертью. В одном случае она является естественной - умирает старая бабушка, в другом - преднамеренной - забивают свинью, в третьем - неожиданной и нелепой - друг, играя в прятки, закрывается в холодильнике, из которого не может выйти. Сам герой в одно время работает могильщиком, в другом эпизоде является сержантом на войне. Каждый раз происходит приобщение Захара к вечному смыслу бытия, проверяющему в человеке нравственный потенциал. Жизнь может резко оборваться и стать смертью, а может быть и наоборот, когда смерть героя обретает черты нового этапа его духовного преобразования и обретения им высшей степени свободы.

Ключевые слова: роман 3. Прилепина «Грех»; тема смерти; жизнеутверждающий смысл; нравственный потенциал; духовное преображение.
\end{abstract}

\section{Для цитирования:}

Берёзкина Е. П., Томина А. Е. Тема смерти как олицетворение жизнеутверждающего смысла в романе Захара Прилепина «Грех» // Вестник Бурятского государственного университета. Язык. Литература. Культура. 2020. Вып. 2. С. 53-60.

Большинство пишущих о 3. Прилепине отмечают, что он талантливый продолжатель традиций литературы реалистического направления. Его творчеству присуще использование приемов антитезы, контраста, которые являются характерными для современного реализма в отечественной прозе, поскольку и самой жизни, и творчеству присуще противоречие, отражающееся в произведениях через противопоставление сюжетных ситуаций, мотивов, героев, их мыслей и чувств [1-5].

Известный писатель и публицист Дмитрий Быков характеризует Прилепина как исключительного профессионала в своем деле. О творчестве писателя положительно отзываются критики Павел Басинский, Юлия Щербинина, Дмитрий Володихин и многие другие. Литературоведы едины во мнении, что Прилепин - 
«в большей степени добрый писатель, что тоже большая редкость сегодня», особо отмечают то, что он очень трудолюбив, весьма востребован и читаем, а также не боится общественного мнения [1].

С этим сложно не согласиться, факт того, что творчество Прилепина находит отклик у читателя, является неоспоримым. В настоящее время при огромном количестве современных авторов, насыщенности массовой литературой заслугой писателя можно назвать стремление к честному и искреннему диалогу с читателем.

Критик и публицист Капитолина Кокшенева утверждает, что проза Прилепина - «энергетическая». «В ней доминирует настоящая сила жизни, крепко заточенная им в слово. Он пришел из России, а потому не хочет и не может жить вполпамяти и вполсилы. Такой у него драйв. Этим крепким инстинктом жизни, принятием ее всякой-разной, всякой-любой, кажется, и особенно привлекательно творчество Захара Прилепина для современников», - пишет Кокшенева во вступительной статье к его книге [7, с. 14].

Мнений о творчестве и личности Захара Прилепина на сегодняшний день достаточно много, например, журналист и критик Андрей Мирошкин характеризует его так: «Прилепин - писатель, безусловно, талантливый, хотя и сыроватый еще местами. Шершавый и грубый - и донельзя лиричный. Революционеррадикал - и колоритнейший деревенщик. Баталист - и бытописатель русских провинциальных нравов. Среди его персонажей - и патологические сволочи, и неисправимые добряки. Он расставляет акценты с истинно русским размахом» $[6$, c. 6].

Роман Захара Прилепина «Грех» (2007) на первый взгляд представляет собой сборник разрозненных небольших историй, но это композиционно целостное художественное произведение с глубоко философским контекстом, который усиливается с каждой страницей книги с усложнением и трансформацией главного героя от рассказа к рассказу [5].

Например, в одноименном рассказе «Грех» автор изображает изменение героя, его нравственное взросление. Так, вначале Захар - подросток, живущий беспечно, беззаботно: «Ему нравилось жить легко, ежась на солнце, всерьез не размышляя никогда» [7, с. 61], к концу же рассказа он становится юношей, ответственным за свои мысли и поступки, преодолевающим свои страсти, контролирующим желания. Цельность личности ребенка с возрастом сохранить невозможно, столкновение с жизнью приводит героя к новому осознанию окружающего мира и самого себя. На первый взгляд, обычное для деревенского жителя дело - забой свиньи - побуждает городского мальчишку, увидевшего это впервые, осознать нелепость жизни и возможность смерти: «Живое существо... оказалось ничтожным, никчемным, его можно было разрезать, расчленить, растащить по кускам» $[7$, с. 71].

Внутренний самоанализ позволяет герою понять, что смерть живого существа нельзя воспринимать однолинейно, одномерно. Захар воочию убеждается в беспомощности свиньи перед смертью, убитая и разделанная туша лишь на миг вызывает в нем жалость, а потом возникает ощущение «сладости смерти». Автор пишет, что его герой почувствовал жизнь «в самом настоящем, первобытном ее виде», соотнеся это с собой, своим животным началом («собственной теплой, 
влажной животностью»), именно это послужило толчком к его взрослению, «перевернуло» его отношение к жизни и самому себе [7, с. 72].

Прилепин показывает сложный процесс взросления 17-летнего героя, Захар мучительно преодолевает свои физиологические потребности в отношении старшей двоюродной сестры, «которую он юношески, изломанно, странно любил» $[7$, с. 55]. Общение с сестрой, молодой красивой женщиной, в яблоневом саду или у реки становится настоящим искушением для подростка. Имеющиеся представления героя о нравственности не позволяют ему сделать неверный шаг, он осознает греховность своей страсти и преодолевает ее, мысленно убивая в себе плотское начало.

В финале рассказа главный герой уезжает из деревни, разрывая тем самым круг искушения. Он верит в то, что у него будет «длинная жизнь» и будет «лето другое». Однако повториться подобное не может, Захар прежним подростком сюда уже никогда не вернется, и автор вполне логично заключает, что «другого лета не было никогда» [7, с. 88]. Критик Игорь Фролов в статье «Смертный грех Захара Прилепина» дает очень точное определение рассказу, называя его: «последний репортаж из рая - про лето юности, когда душа только начинает пробиваться из куколки тела...» $[8$, с. 9].

Совсем иная картина мира героя представлена в новелле «Шесть сигарет и так далее». Захар по неизбежности оказывается на должности охранника, эту работу нельзя считать его призванием, но она ему необходима, чтобы прокормить семью. По сравнению с рассказом «Грех», где герой романтичный молодой юноша, в этой новелле Захар уже зрелый самостоятельный приземленный жизнью мужчина. То, что происходит в его судьбе теперь, можно охарактеризовать фразой, верно сформулированной им самим: «Мы все время куда-то идем» [7, c. 126].

Мотив пути и движения имеет неопределенность, неосознанность, спонтанность, герой передвигается не по собственной воле, а вопреки желанию. В ряде новелл присутствует сопровождающий мотив ветра: «А добро... легче пуха. Его унесет любым сквозняком...» [7, с. 75-76]; «Каким-то нелепым сквозняком меня понесло в окраинный дом моей школьной подруги...» [7, с. 123]. Таким образом, автор показывает стихийное начало жизни, непредсказуемость судьбы, где жизнь и смерть не подвластны человеческому разумению. Но это не делает героя пассивным фаталистом, наоборот, Захар активно реагирует на происходящее: в рассказе он заступается за честь малознакомых девушек, противостоит хамству бандитов, бесцеремонности бизнесменов, дерзости представителей «золотой молодежи». Работая охранником в ресторане, Захар вынужден драться с нарушителями порядка и спокойствия, но он нередко осознанно и жестоко их избивает. Автор обращает внимание на то, что герою становится неприятно, мерзко от осознания собственных действий, от соприкосновения с такими людьми, которые теряют свой человеческий облик: «Вытер руку о его плащ, но она все равно осталась грязной, осклизлой, гадкой» [7, с. 170].

Большое разнообразие противопоставлений, парадоксальных и алогичных описаний присутствует в рассказе «Карлсон», автору удается показать жизнь героя, складывающуюся из противоречий, которые отражают поиск им самого се- 
бя: «Нежность к миру переполняла меня настолько, что я решил устроиться в иностранный легион, наемником» [7, с. 88]. Он пытается преодолеть в себе то доброе, прекрасное и, возможно, детское, что в нем еще осталось, собираясь работать в иностранном легионе, где смерть, жестокость и насилие будут постоянными явлениями.

Рядом с главным героем в новелле изображен его старый приятель Алеша. «Ему было чуть за тридцать, он закончил Литературный институт и служил в армии, где его немыслимым для меня образом не убили» [7, с. 91]. С одной стороны, герой учился в Литературном институте, то есть был творческой личностью, с другой стороны, столкнулся с жестокостью и бессмысленностью армейской службы, - явное противоречие.

Само название рассказа «Карлсон», поведение героя, его внешность отсылают читателя к детской сказке А. Линдгрен про Малыша и Карлсона: «Болезненно толстый человек... Черты лица расползшиеся, словно нарисованные на сырой бумаге» [7, с. 89], «любил говорить» и «перебивал, не дослушав» [7, с. 90, 94]. Такие реминисценции заданы автором неслучайно, читатель отталкивается от известного ему образа и входит в совершенно другое смысловое поле.

Алеша становится неким двойником Захара, не похожим внешне, но соответствующим внутренне. В них обоих заложено романтическое начало, свойственное молодости, которое проявляется в их одиночестве и противопоставленности остальному миру, неприспособленности к жизни в разных ее проявлениях, стремлении уйти в иную реальность, используя спиртные напитки и выдумывая другое бытие в своих историях, нераскрывшийся талант личности художника. Возможно, поэтому присутствует какая-то неясность в их взаимоотношениях и разрушительное начало, завершающееся разрывом. Можно предположить, что в рассказе изображена «смерть» дружбы, означающая для Захара возрождение к новой жизни. Разочарование героя Алешей-Карлсоном неизбежно, поскольку их отношения несут деструкцию, их разрыв оборачивается обновлением, обретением себя.

Общее безоблачное и радостное настроение начала рассказа «Ничего не будет» имеет обратный смысл, который заключается в недолговечности, неустойчивости счастья, что и прослеживается с первых строк. Старший сын Захара, пятилетний малыш, с любопытством спрашивает, все ли люди смертны: «Мама, а все умирают или не все?» [7, с. 180]. Отец не хочет думать о смерти, потому что счастлив, но слова сына заставляют его вспомнить о неотвратимости жизненного пути. Мотив смерти присутствует не только в умозаключениях героев, но и реально проявляется в известии о смерти бабушки Захара.

Автор вводит троичность мотива, т. е. он трижды повторяется, усиливаясь. Вначале это абстрактный вопрос ребенка, затем известие о реальной смерти бабушки, отсылающее к детским воспоминаниям самого Захара о том, что он когда-то давно со страхом думал об этом, и, наконец, возникшая угроза смерти самого героя от выехавшей навстречу машины, с которой он мог столкнуться. «Дальнобойщик около ста метров ехал по встречной, а потом свернул на свою полосу, так и не остановившись, чтобы сказать мне, что я... Что я смертен» [7, c. 185]. 
E. П. Берёзкина, А. Е. Томина. Тема смерти как олицетворение жизнеутверждающего смысла в романе Захара Прилепина «Грех»

Мотив смерти обретает философский, онтологический смысл, объединив три разных поколения одной семьи, несет в себе горечь потери (смерть любимой бабушки Захара), указывает на продолжение жизни, рода (у бабушки остались внук и правнук) и заставляет понять, что любой человек смертен, поэтому надо ценить жизнь, каждое ее мгновение.

В рассказе «Колеса» мотив смерти приобретает наивысшую концентрацию уже с первых строк - действие начинается на кладбище, а герои повествования каждый день сталкиваются со смертью. Автор показывает отстраненность Захара и его товарищей, их внешнее безразличие к чужой смерти, которую они видят постоянно. Хоронить людей, рыть могилы - такова их работа, ее тоже нужно кому-то выполнять. Ежедневное столкновение со смертью притупило чувство сострадания, но не уничтожило его совсем. В глубине их сущности осталось то, что отзывается болью, поэтому герои пьют, пытаясь заглушить образовавшуюся внутреннюю пустоту - хоронят собственные души.

Финал рассказа становится неким потрясением для героя. В нетрезвом состоянии Захар не может перейти через рельсы на железнодорожных путях, падает в насыпь, и в этот момент прямо перед ним проносится товарный поезд: «...увидел, как перед глазами со страшным грохотом несутся черные блестящие колеса. ...Огромные колеса сжигали воздух, оставляя ощущение горячей, душной, бешеной пустоты» [7, с. 129]. Несколько минут как будто создали для Захара ощущение ада, из которого он пока еще в состоянии вырваться. Именно в этот момент герой приходит к неутешительному выводу о том, что «каждый год... ты переживаешь день своей смерти» [7, с. 129]. Игорь Фролов, сравнивая рассказы, приходит к следующему весьма эмоциональному заключению: «Если рассказ "Грех" - это кульминация книги, ее солнечный июльский полдень, то рассказ "Колеса" - точка, яма, из которой тянет падалью» [9, с. 440].

Усиление противостояния жизни и смерти ярко выражено в сюжетной линии рассказа «Белый квадрат». В детстве у Захара был друг Саша, который «позволял себе смеяться над местными криволицыми и кривоногими хулиганами» [7, с. 188]. С ним связано одно из самых страшных воспоминаний детства: мальчик трагически погиб, спрятавшись во время игры в холодильник, из которого не смог выбраться; дети с наступлением сумерек разошлись по домам, и Захарка не смог найти друга.

По его детским представлениям, Саша был «необыкновенный», с лицом «нежной красоты», «всегда» готовый «вспыхнуть осмысленной, чуткой улыбкой». Он не заслуживал смерти, и тем она казалась герою еще более ужасна и несправедлива [7, с. 188]. Саша воспринимается Захаром как идеал, он не может забыть друга и, уже став взрослым, он продолжает мысленно с ним общаться. Умерший в детстве друг становится символом совести главного героя. «Теперь оказывается, что у героя романа есть вина за чужую смерть - она, как червяк в румяном яблоке детства, первый его грех. <..> Рассказ дан последним в первой части книги, и теперь читатель может примерить этот грех ко всему страшному, что он уже прочитал о жизни героя», — отмечает И. Фролов [9, с. 449].

Мотив обесценивания жизни и близости смерти пронизывает заключительный рассказ «Сержант». Герой «сделал выбор: ему так казалось, что сделал». 
«Он, мнилось ему, выцарапал себе право не беречь себя и уехал» [7, с. 238]. С одной стороны, он является отцом, поэтому «больше не имеет права умирать, когда ему захочется» [7, с. 237]. С другой стороны, он осознанно принял решение быть там, где идет война, и где могут убить в любую минуту: "Не думаю, не думаю, не помню никого, самых близких и самых родных не помню", — отмахнулся от себя же, понимая, что если помянет другую свою, разлитую в миру кровь по двум розовым, маленьким, пацанячьим, цыплячьим телам, то сразу сойдет с ума» $[7$, с. 254].

В целом представления о жизни и смерти, о свободе выбора, которые пронизывают все рассказы, сформулированы героем здесь одной фразой: «Невозможность легкости при главном выборе» [7, с. 238]. Внутренний психологический процесс осуществления столь важного решения лишь пунктиром намечен в произведении. Вся сложность заключается в том, что сержанту приходится принимать решение не только за себя, но и за тех молодых ребят, которые находятся в его подчинении и вместе с ним оказываются отрезаны от остальной части.

Страх охватывает героя, и автор передает это состояние через невозможность человека оставаться в вертикальном положении, он вынужден падать на землю, лежать, ползти: «Медленно, медленнее растущего цветка, он проползал последние метры до машины» [7, с. 257]. Более того, ранее сержант уже осознал это как ненормальное состояние пресмыкающегося, в котором находится не только один человек или группа людей, а вся страна: «Что же это творится в моей стране... Почему я ползаю по ней...» [7, с. 251]. Автор показывает, как через душевную боль, растерянность, чувство вины, беспомощности усиливается страх героя, и нужно обладать большой силой, чтобы суметь преодолеть его в себе.

В финале рассказа сержант берет ответственность на себя и делает последний решительный шаг навстречу смерти и свободе: «...неожиданно легко встал на ноги и сделал несколько очень мягких, почти невесомых шагов» [7, с. 261]). Прилепин не констатирует смерть героя, а изображает это через возможность отделения духовного тела от физического, когда первое с высоты наблюдает за вторым. Д. Володихин комментирует данный эпизод следующим образом: «...в данном случае физическую смерть можно рассматривать как душевное освобождение героя, переход на новый уровень (неслучайно сначала Сержант как будто не замечает своей смерти, а потом наблюдает мертвое тело со стороны)» [2].

В связи с лейтмотивом книги «жизнь - смерть», где две категории находятся иногда в такой близости, что грань между ними стирается, смерть героя представляется закономерным финалом, который неоднократно предсказывается как в предыдущих новеллах, так и в заключительной. Однако, с другой стороны, трагический финал становится новым этапом духовной трансформации героя и провозглашает обретение им новой степени свободы.

Критики указывают на то, что главный герой в рассказе постепенно становится близок и понятен читателю, «можно представить образ этого решительного и смелого человека, можно переживать и, несмотря на указания автора на трагический финал, внутренне ждать счастливой развязки. И в тот самый момент, когда образ сержанта становится наиболее ощутим, ярок и объемен, герой погибает. Погибает таким образом, что в подобный исход не хочется верить до конца, погибает в тот момент, когда хочется верить в его победу» [1]. 
В финале романа максимально обнажается «оголенный нерв» повествования, свойственный Прилепину, расположенный автором на границе извечных категорий жизни и смерти. Как только читатель поверил в торжество жизни, писатель возвращает его в реалистическое бытие, и наоборот, в тот момент, когда сержант погибает и надежды, казалось бы, не остается, писатель с характерной поэтичностью ставит многоточие и призывает верить в безграничность возможностей [10].

Если в самом начале одна важная мысль звучала как набросок и эскиз, то в единстве формы романа она звучит как лейтмотив произведения: «Смерть означает жизнь», даже если и не под тем углом, под которым мы привыкли смотреть. Отказ от работы в иностранном легионе, потеря любимого близкого человека или товарища, даже гибель самого главного героя еще раз напоминают о силе и торжестве жизни, ее новом витке и продолжении.

На наш взгляд, в упомянутых выше сюжетах наиболее ярко олицетворен собирательный образ героя, каждый день сталкивающегося с необходимостью выбора и ответственности за свои поступки. Философско-культурный контекст произведения проявляется через описание жизненных ситуаций, зачастую бытовых, которые неизбежно заставляют задуматься о базовых моральных ценностях и ориентирах и выводят героя на бытийный уровень.

На примере Захара видно, как автор изображает различные ситуации через призму чувств и решений своего персонажа. Писателю в повествовании важны не сами факты осуществившихся событий, а те реакции, которые они оставляют в душе главного героя. Автор в своем произведении неоднократно затрагивает серьезные темы, в которых Захар поступает согласно своим внутренним принципам, не всегда созвучным с мнением большинства, не всегда находящимся в согласии с его собственными желаниями. Однако, несмотря на возраст героя, степень драматизма событий и его вовлеченность в них, Захар для читателя остается чувствующим и неравнодушным человеком: мальчиком, юношей, мужчиной или солдатом, умеющим любить близких, защищать слабых и достойным уважения. Захар Прилепин использует различные приемы усиления художественной выразительности и подчеркивает философский контекст романа путем противопоставления категорий жизни и смерти, их переплетения и существования в единстве друг с другом.

Литература

1. Захар Прилепин: официальный сайт писателя [Электронный ресypc]. URL: http://www.zaharprilepin.ru (дата обращения: 18.03.2020).

2. Володихин Д. Чувство бога [Электронный ресурс] // Политический журнал. 2007. № 29(172). URL: https://zaharprilepin.ru/ru/pressa/greh/politicheskij-zhurnal.html (дата обращения: 17.03.2020).

3. Зацепина М. Захар Прилепин: «Некоторые не попадут в ад» // Университетская книга. 2019. № 5. С. 72-73.

4. Кубанова А. А. Идеи жизни, смерти и счастья как объединяющие роман в рассказах 3. Прилепина «Грех» // Научный вестник Кубанского государственного университета. Медиакоммуникация. 2016. № 1(2). С. 81-85.

5. Местергази Е. Г. Жанровое своеобразие романа Захара Прилепина «Грех» // Проблемы поэтики и стиховедения: материалы V Междунар. науч.-практ. конф., посв. 
памяти и 70-летию д-ра филол. наук, проф. В. В. Бадикова (15-16 октября 2009 г.). Алматы, 2009. С. 191-195.

6. Мирошкин А. Шершавое счастье // Книжное обозрение. 2007. № 36/37. С. 6.

7. Прилепин 3. Грех и другие рассказы. М.: АСТ: Астрель, 2018. 420 с.

8. Фролов И. Закон сохранения страха. «Грех» Захара Прилепина как национальный бестселлер // Континент. 2009. № 139. С. 435-451.

9. рролов И. Смертный грех Захара Прилепина [Электронный ресурс] // Независимая газета EX LIBRIS. 2009. № 139. 26 февраля. URL: http://www.ng.ru/ng_exlibris/200902-26/4_zhar.html (дата обращения: 18.03.2020).

10. Янковская Л. С. Система ценностей главного героя книги 3. Прилепина «Грех» // Известия Самарского научного центра Российской академии наук. Социальные, гуманитарные, медико-биологические науки. 2016. Т. 18, № 1(2). С. 277-280.

\title{
THEME OF DEATH AS A REIFICATION OF LIFE AFFIRMING IDEA IN ZAKHAR PRILEPIN'S NOVEL "SIN"
}

\author{
Elena P. Berezkina \\ Cand. Sci. (Phil.), A/Prof., \\ Dorzhi Banzarov Buryat State Univtrsity \\ 6 Ranzhurova St., Ulan-Ude 670000, Russia \\ beryozkina-lena@yandex.ru
}

\author{
Anna E. Tomina \\ Student, \\ Dorzhi Banzarov Buryat State University \\ 6 Ranzhurova St., Ulan-Ude 670000, Russia \\ anna.tomina999@yandex.ru
}

Abstract. The article considers the theme of death as a reification of life-affirming idea in
the novel by Zakhar Prilepin "Sin". His hero, Zakhar, was shown as a boy, an adolescent, an
adult male, and a father of his sons, and at all these different stages of development he con-
stantly faced death: in one case it was natural — an old grandmother died, in the other it
was deliberate - they slaughtered a pig, in the third the death was unexpected and ridicu-
lous - his friend, playing hide and seek, locked himself in the refrigerator, from which he
could not get out. The hero himself at one time worked as a gravedigger, in another - he
was a sergeant in the war. Zakhar constantly got a feel for the eternal purpose of existance,
which tested the moral potential of a person. Life can abruptly end and become death, or
vice versa, the hero's death can acquire the features of a new stage of his spiritual transfor-
mation and he attains the utmost freedom.

Keywords: Z. Prilepin's novel "Sin"; the theme of death; life-affirming idea; moral potential; spiritual transformation. 